\title{
EFECTO DE DIETAS ARTIFICIALES EN LA BIOLOGÍA DE ADULTOS DE CHRYSOPERLA EXTERNA (HAGEN, 1861) (NEUROPTERA: CHRYSOPIDAE)
}

\author{
José SoTO ${ }^{1}$ y José IANNACONE ${ }^{1,2}$ \\ ${ }^{1}$ Facultad de Ciencias Naturales y Matemática, Universidad Nacional Federico Villarreal. \\ Calle San Marcos 383, Pueblo Libre, Lima 29, Lima, Perú. \\ 2Laboratorio de Invertebrados. Facultad de Ciencias Biológicas, Universidad Ricardo \\ Palma, Avenida Benavides 5440, Lima 33, Surco, Lima, Perú. \\ E-mail: joseiannacone@gmail.com
}

\begin{abstract}
RESUMEN
Se evaluó bajo condiciones de laboratorio el efecto de ocho dietas sobre la biología de adultos de Chrysoperla externa (Hagen, 1861) (Neuroptera: Chrysopidae) con el fin de determinar una dieta artificial barata y efectiva. Una dieta estándar con levadura y siete constituidas por maca (Lepidium meyenii Walpers), soya (Glycine max (Linnaeus) Merril) y kiwicha (Amaranthus caudatus Linnaeus); en las siguientes combinaciones: levadura y maca; levadura y kiwicha; levadura y soya; levadura, maca y kiwicha; levadura, maca y soya; levadura, soya y kiwicha; y levadura, maca, soya y kiwicha fueron evaluadas con respecto a la biología de adultos de C. externa. Todas las dietas contenían miel de abejas, polen y agua. Se evaluó la influencia de las dietas de los adultos en la viabilidad de los huevos, capacidad de oviposición, ritmo de oviposición, periodo de pre-oviposición, periodo de oviposición, periodo de post-oviposición de las hembras y longevidad de hembras y machos, durante dos generaciones de C. externa. Las ocho dietas evaluadas obtuvieron una elevada viabilidad de huevos en condiciones de laboratorio. Sin embargo, las dietas estandarizada a base de levadura, levadura + kiwicha, y soya + kiwicha obtuvieron una más alta viabilidad de huevos. Las dietas a base de levadura, levadura + maca, levadura + kiwicha, y a base de maca y kiwicha fueron con las que se obtuvo la mayor capacidad de oviposición. En general, no existieron diferencias significativas entre los periodos de preoviposición, oviposición y post-oviposición bajo las ocho dietas artificiales para C. externa, con tendencia a ser más altos en la segunda generación. Las dietas de levadura con maca, levadura, maca, soya y kiwicha permitieron un aumento en la longevidad de las hembras y machos para la segunda generación.
\end{abstract}

Palabras clave: adultos, Chrysoperla externa, dieta, kiwicha, maca, soya.

\begin{abstract}
The effects of eight diets on the biology of adult of Chrysoperla externa (Hagen, 1861) (Neuroptera: Chrysopidae) were evaluated under laboratory conditions with aims at identifying effective low cost artificial diets. A standard diet with yeast extract and seven diets composed of maca (Lepidium meyenii Walpers), soybean (Glycine max (Linnaeus) Merril) and amaranth (Amaranthus caudatus Linnaeus), in the following combinations: yeast extract plus maca, yeast extract plus amaranth, yeast extract plus
\end{abstract}


soybean, yeast extract plus maca plus amaranth, yeast extract plus maca plus soybean, yeast extract plus soybean plus amaranth, and yeast extract plus maca plus soybean plus amaranth were evaluated on the biology of adults of C. externa. All diets contained honeybee, pollen and water. The influence of adult diets on viability of eggs, female fecundity, pre-oviposition period, oviposition period, post-oviposition period, male and female longevity during two generations of $C$. externa was evaluated. The eight diets tested obtained high viability of eggs under laboratory conditions. However, diets containing yeast extract, yeast extract plus amaranth, and soybean plus amaranth reached higher viability of eggs. Diets of yeast extract, yeast extract plus maca, yeast extract plus amaranth, and maca plus amaranth were those that obtained the highest fecundity. In general, no significant differences were found between preoviposition period, oviposition period, post-oviposition period under eight artificial diets for C. externa, but there was a tendency to be higher in second generation. Diets with yeast extract plus maca, yeast extract plus maca plus soybean plus amaranth permitted an increase of female and male' longevity in the second generation.

Key Words: adults, amaranth, Chrysoperla externa, diets, maca, soybean.

\section{INTRODUCCIÓN}

Chrysoperla es uno de los géneros que tiene mayor importancia dentro de la familia Chrysopidae (Neuroptera), por considerarse a sus especies como insectos benéficos en el control biológico (Nuñez 1988a, Chang et al. 2000, Miller et al. 2004). También son fáciles de criar en cautiverio y en estado larval son muy voraces prefiriendo como presas a insectos de cuerpo blando. Chrysoperla externa (Hagen), destaca como controlador biológico por sus características depredadoras, amplia distribución, presencia de adultos todo el año, fácil crianza en cautiverio, potencial para adaptarse a varios ambientes de cultivo y su resistencia a numerosos plaguicidas (Núñez \& Pardo 2002, Cardoso \& Lazzari 2003, Medina et al. 2003). Esta especie presenta gran voracidad en estado larval y en estado adulto, y se le ha registrado depredando un amplio rango de insectos de cuerpo blando, especialmente huevos y larvas de lepidópteros como Spodoptera frugiperda (Smith, 1797), Spodoptera eridania (Stoll, 1782), Helicoverpa zea (Boddie, 1850), Cydia pomonella (Linnaeus, 1758), Pectinophora gossypiella (Saunders, 1843) como áfidos en el cultivo de maíz. En olivo, se encuentra alimentándose de Orthezia olivicola Beingolea, 1965 (Núñez 1985, Nuñez 1988a, Iannacone \& Murrugarra 2000, Iannacone \& Lamas 2002, 2003, Miller et al. 2004). Además de estar considerada en programas de Manejo Integrado de Plagas (MIP) del Programa Nacional de Control Biológico (PNCB), se producen masivamente en los laboratorios de control biológico del Perú, para su distribución y sostenimiento de programas de MIP (Nuñez 1988b).

Se han desarrollado dietas artificiales para adultos de Chrysoperla carnea (Stephens, 1836) constituidas por proteína enzimática hidrolizada de levadura de cerveza, logrando obtener 786 huevos por hembra durante 21 días, en comparación con 391 huevos por hembra cuando se les suministró solo polen y miel natural 
(Ulhaq et al. 2006). Vanderzant (1969) evaluó como alimento para larvas de C. carnea una dieta artificial constituida por lecitina de soya y aceite, colina, inositol y ácido ascórbico en agua. Vanderzant (1973) demostró que la falta de lecitina de soya enzimática hidrolizada y la caseína reducían la emergencia de los adultos. Ridway et al. (1970) evaluaron adultos de C. carnea alimentándolos con levadura. Martín et al. (1978) mencionan que entre las dietas más importantes para la producción de huevos de $C$. carnea se encontraron aquellas compuestas con sucrosa, y levadura y sucrosa. Se determinó que la sucrosa más levadura logró un incremento del $38 \%$ de huevos por día por hembra en comparación al alimento natural (Tassan et al. 1979).

Se ha evaluado a los adultos de C. externa con dietas artificiales, levadura de cerveza, proteína hidrolizada y levadura más polen, adicionándoles a todos estos componentes agua destilada y miel de abeja, obteniéndose una mayor capacidad de oviposición y más alta fertilidad con dieta a base de levadura (Lizárraga \& Cañedo 1988). Campoverde et al. (2002) realizaron una producción masiva en laboratorio de C. externa, usando una dieta modificada para adultos con maca Lepidium meyenii Walpers agregando a la dieta convencional, basada en levadura de cerveza, miel, polen y agua. Se ha observado que los niveles de producción de huevos fueron similares con ambas dietas y que no hubo rechazo del insecto adulto por la dieta modificada. Otros autores proponen como dieta estándar para adultos de C. externa, levadura de cerveza y miel (Boregas et al. 2003, Lira \& Batista 2006).

La maca L. meyenii (Brassicaceae) es una herbácea, pequeña, pegada al suelo y domesticada, cuya distribución abarca principalmente la sierra del Perú, entre los 3500 a $4500 \mathrm{msnm}$. Se le usa como alimento, medicina, afrodisíaco, forraje y en etnoveterinaria. Las raíces cocidas tienen entre 13 y $16 \%$ de proteína, y son ricas en aminoácidos esenciales (Canales et al. 2000, Brack 2003, López-Fando et al. 2004, Valerio \& Gonzáles 2005, Gonzáles \& Valerio 2006).

La soya Glycine max (Linnaeus) Merril (Fabaceae) es una planta herbácea anual. Su semilla generalmente es esférica de color amarillo. Su centro de origen se sitúa en el Extremo Oriente (China, Japón, Indochina). La semilla es rica en proteínas y en aceites. En algunas variedades mejoradas presenta alrededor del 40-42\% de proteína y del 20-22 \% en aceite, respecto a su peso seco. En la proteína de soya hay un buen balance de aminoácidos esenciales, destacando lisina y leucina. La soya es una excelente fuente de proteínas de buena calidad, que puede compararse satisfactoriamente con otros alimentos proteicos. El aceite de soja es rico en ácidos grasos poliinsaturados y no contiene colesterol. La soya también es una buena fuente de calcio, hierro, cinc, fosfato, magnesio, vitaminas B y folatos (Karr-Lilienthal et al. 2006, Mahmoud et al. 2006). Se ha encontrado que G. max tiene efectos positivos sobre el desarrollo biológico de los adultos de Homalodisca coagulata (Say, 1832) (Homoptera: Cicadellidae) (Brodbeck et al. 2004). 
La kiwicha Amaranthus caudatus Linnaeus (Amaranthaceae) es una hierba anual domesticada de tallo angular, suculenta, cuya distribución va desde los andes de Colombia hasta Argentina. Se le usa como alimento, forraje para ganado, ornamento y medicina. El contenido de proteína de los granos fluctúa entre el 13 y $18 \%$, con altos niveles de lisina (Chávez-Jáuregui et al. 2000, Bruni et al. 2001, Brack 2003).

El presente trabajo tuvo como objetivo determinar la influencia de siete dietas artificiales a base de maca, soya y kiwicha sobre la biología de adultos de C. externa, evaluando la viabilidad de huevos, la capacidad de oviposición, el ritmo de oviposición, los periodos de pre-oviposición, oviposición y post-oviposicición, y finalmente la longevidad de los adultos, con el fin de reducir los costos de crianza e incrementar su producción en laboratorio.

\section{MATERIAL Y MÉTODOS}

El trabajo de investigación se realizó en los laboratorios de crianza de insectos benéficos del PNCB, Servicio Nacional de Sanidad Agraria (SENASA), con sede en calle Los Diamantes s/n Ate-Vitarte, distrito de Lima (1201'18" LS, 76 54 '57' LO) a una altitud de $352 \mathrm{~m}$ snm. Los experimentos se realizaron en laboratorio bajo condiciones no controladas, a temperatura promedio de $25 \pm 4{ }^{\circ} \mathrm{C}$, humedad relativa de 47 a $65 \%$ y fotoperiodo 12:12 (Cuadro 1).

Cuadro 1. Temperatura y humedad relativa registrados durante la crianza de C. externa.

\begin{tabular}{ccccc}
\hline Meses & $\begin{array}{c}\text { Temp. } \\
\text { Max }{ }^{\circ} \mathrm{C}\end{array}$ & $\begin{array}{c}\text { Temp. } \\
\text { Min }{ }^{\circ} \mathrm{C}\end{array}$ & $\begin{array}{c}\text { Temp. } \\
\text { Promedio }\end{array}$ & $\begin{array}{c}\text { Humedad } \\
\%\end{array}$ \\
\hline marzo & 28,3 & 26,4 & 27,4 & 50,5 \\
abril & 27,1 & 25,4 & 26,3 & 51,8 \\
mayo & 23,4 & 21,6 & 22,5 & 62,3 \\
junio & 21,5 & 19,7 & 20,6 & 64,4 \\
\hline julio & 21,0 & 19,2 & 20,1 & 63,0 \\
agosto & 21,4 & 19,9 & 20,7 & 57,0 \\
septiembre & 21,3 & 19,5 & 20,4 & 62,0 \\
octubre & 22,2 & 20,4 & 21,3 & 59,3 \\
\hline t & & & 2,21 & 0,10 \\
Sig & & & 0,81 & 0,46 \\
\hline
\end{tabular}

$\mathrm{t}=$ Prueba de $\mathrm{t}$ de Student. Sig $=$ Significancia. 


\section{Crianza de Chrysoperla externa}

La crianza larval masiva de C. externa se realizó empleando huevos de Sitotroga cerealella (Iannacone \& Lamas 2002, Iannacone et al. 2007). Se seleccionaron 200 pupas de C. externa provenientes de la crianza de crisópidos del PNCB-SENASA, éstas fueron acondicionadas en jaulas de dos mangas o jaulas de pre-oviposición, hasta la emergencia de los adultos y mantenidas con una dieta artificial estándar a base de miel, agua y polen, hasta alcanzar la madurez sexual. Posteriormente fueron sexados según la conformación del abdomen y su terminación con respecto a la genitalia externa. Luego se colocó una hembra y un macho en envases cilíndricos de plástico de 11 de capacidad, de $11,5 \mathrm{~cm}$ de alto por $12 \mathrm{~cm}$ de diámetro (unidades de oviposición y alimentación). Ocho dietas artificiales fueron probadas individualmente, siete dietas artificiales fueron elaboradas a base de maca (M), soya (S) y kiwicha (K), además de la dieta estándar con las que se alimentaron a las parejas de C. externa en las unidades de oviposición y alimentación, realizándose ocho repeticiones para cada dieta. El Cuadro 2 muestra comparativamente las concentraciones de los aminoácidos presentes en las harinas de maca, soya y kiwicha, componentes de las dietas evaluadas para la crianza de adultos de $C$. externa.

Cuadro 2. Aminoácidos en la maca, soya y kiwicha en $\mathrm{mg} \cdot 100 \mathrm{~g}-1$ de proteína.

\begin{tabular}{lccc}
\hline Aminoácidos & Maca & Kiwicha & Soya \\
\hline Arginina & 99,4 & 75 & - \\
Leucina & 917 & 46 & 78 \\
Isoleusina & 47,4 & 52 & 46 \\
Valina & 79,3 & 45 & 46 \\
Fenilalanina & 55,3 & 35 & 88 \\
Lisina & 54,5 & 67 & 64 \\
Treonina & 33,1 & 51 & 39 \\
Metionina & 28 & 35 & 26 \\
Histidina & 21,9 & 21 & 26 \\
Triptofano & 4,9 & 11 & 14 \\
\hline
\end{tabular}

Fuente: Dini et al. (1994).

La dieta estándar o dieta control (L) es la utilizada por el PNCB-SENASA en la alimentación de adultos de C. externa. En base a esta dieta fueron determinados los tratamientos del 2 al 8 (Cuadro 3). 
Cuadro 3. Dietas artificiales para alimentación de adultos de Chrysoperla externa.

\begin{tabular}{|c|c|c|c|c|c|c|c|c|}
\hline \multirow[b]{3}{*}{ Ingredientes } & \multicolumn{8}{|c|}{ Dietas (g) } \\
\hline & 1 & 2 & 3 & 4 & 5 & 6 & 7 & 8 \\
\hline & $\mathrm{L}$ & $\mathrm{L}+\mathrm{M}$ & $\mathrm{L}+\mathrm{S}$ & $\mathrm{L}+\mathrm{K}$ & $\mathrm{M}+\mathrm{S}$ & $\mathrm{M}+\mathrm{K}$ & $\mathrm{S}+\mathrm{K}$ & $\mathrm{M}+\mathrm{S}+\mathrm{K}$ \\
\hline Maca (Lepidium meyenii) & & 17,5 & & & 8,75 & 8,75 & & 7 \\
\hline Kiwicha (Amaranthus caudatus) & & & & 17,5 & & 8,75 & 8,75 & 7 \\
\hline Soya (Glycine max) & & & 17,5 & & 8,75 & & 8,75 & 7 \\
\hline Levadura de cerveza & 35 & 17,5 & 17,5 & 17,5 & 17,5 & 17,5 & 17,5 & 21 \\
\hline Polen & 1,75 & 1,75 & 1,75 & 1,75 & 1,75 & 1,75 & 1,75 & 3,5 \\
\hline Miel & 17,5 & 17,5 & 17,5 & 17,5 & 17,5 & 17,5 & 17,5 & 21 \\
\hline Agua & 17,5 & 17,5 & 17,5 & 17,5 & 17,5 & 17,5 & 17,5 & 21 \\
\hline
\end{tabular}

Para la preparación de las ocho dietas se usó como medida una cucharadita de aproximadamente 3,5g $\mathrm{L}=$ levadura de cerveza; $\mathrm{M}=$ maca; $\mathrm{S}=$ soya $\mathrm{K}=$ kiwicha. La dieta estándar para adultos de $\mathrm{C}$. externa usada en el PNCB-SENASA es la $\mathrm{N}^{\circ} 1$.

Las unidades de oviposición fueron forradas por dentro con papel kraft, para recuperar los huevos ovipositados, teniendo cuidado en fijarlo bien a las paredes internas del envase para evitar que las crisopas quedaran atrapadas entre el papel y las paredes del envase. También se colocó papel kraft con una abertura cuadrada de $3 \mathrm{~cm}$ de lado a manera de tapa, asegurándola con una liga y sobre ésta se colocó la tapa del envase, a la cual previamente se le había hecho una abertura central de 5 cm de diámetro, que se cubrió con organza y se fijó con pegamento (Terokal“) por sus bordes; sobre la cual se puso algodón humedecido con agua. Las parejas de $C$. externa fueron alimentadas con las dietas correspondientes, éstas les fueron proporcionadas en paletas plásticas de $10 \times 3 \mathrm{~cm}$ formando una línea delgada, para evitar que las crisopas quedaran pegadas al alimento. Las evaluaciones se realizaron para la primera generación (Rango de Temperatura Promedio de 20,6 ${ }^{\circ}$ a $27,4{ }^{\circ} \mathrm{C}$ entre marzo a junio del 2005) y para la segunda generación (Rango de Temperatura Promedio de $20,1{ }^{\circ} \mathrm{C}$ a $21,3{ }^{\circ} \mathrm{C}$ entre julio y octubre del 2005) de $C$. externa.

Viabilidad de huevos. Se utilizaron 60 huevos ovipositados aproximadamente en la misma fecha, dentro de las $48 \mathrm{~h}$ de cada cambio, estos fueron escogidos al azar del total de huevos puestos por las ocho parejas de cada dieta (tratamiento) y colocados de manera individual dentro de posillos de placas de plástico con 96 posillos de ELISA (BIOREBA ${ }^{\circledR}$ ). Las placas se cubrieron con organza sellando los bordes con 
cinta adhesiva y se colocó una luna de vidrio de las mismas dimensiones de la placa encima de ésta, para evitar la salida de las larvas. Éstos fueron mantenidos en las placas de ELISA hasta la emergencia de las larvas, durante un periodo de cuatro a siete días, después del cual se procedió a contar la cantidad de larvas emergidas respecto al total de huevos, para calcular el porcentaje de viabilidad. El porcentaje de viabilidad se evaluó dos veces para cada tratamiento, una al inicio y otra al final de cada generación.

Capacidad de oviposición. Cada 48 h, las unidades de oviposición de los ocho tratamientos acondicionadas con los adultos, fueron cambiadas por otras nuevas con el fin de colectar las posturas, para lo cual se procedió primero a quitar el algodón, se retiró la tapa del envase y se golpeó suavemente con la palma la tapa de papel kraft para que las crisopas se desprendieran de ésta. Rápidamente se retiraron la paleta de alimentación, las ligas y la tapa de papel kraft y se tomaron las crisopas con la ayuda de un tubo de boca ancha colocando cada pareja en una nueva unidad de oviposición (envase) a la cual se le repuso el alimento, el algodón embebido en agua y se acondicionó de la forma anterior. Después se retiró cuidadosamente el papel kraft del envase y se procedió al conteo de los huevos puestos sobre éste, posteriormente se retiraron los huevos cortando su pedicelo con una tijera y fueron depositados sobre placas petri para ser limpiados y separados para las pruebas siguientes. El cambio de unidades de oviposición y conteo de huevos puestos por cada hembra, se realizó hasta su muerte.

Ritmo de oviposición. Este fue determinado mediante la observación y registro diario de la variación en la cantidad de huevos puestos por cada una de las ocho hembras de los tratamientos, a lo largo del periodo de oviposición desde la fecha de inicio de las primeras posturas, que se da después del periodo de pre-oviposición hasta el inicio el periodo de post-oviposición.

Periodo de pre-oviposición, oviposición y post-oviposición. Antes del inicio del periodo de oviposición, se presenta un periodo de pre-oviposición, en el cual los adultos alcanzan la madurez sexual y se vuelven aptos para la cópula, posteriormente se da el periodo de oviposición, para finalmente entrar al periodo de postoviposición, que comprende desde la última postura hasta la muerte de las hembras. El tiempo de duración de estos tres periodos en C. externa se determinó mediante la observación directa de las parejas, registrando la fecha de inicio y fin de la oviposición. Estos datos se registraron para las ocho repeticiones de cada dieta o tratamiento.

Longevidad de hembras y machos. La longevidad de hembras y machos de $C$. externa, se determinó teniendo en cuenta la fecha de emergencia de los adultos en la jaula de dos mangas y la fecha de su muerte en las unidades de oviposición. 


\section{Análisis estadístico}

Para probar el efecto de los tratamientos (dietas) sobre la capacidad de oviposición, longevidad de adultos y viabilidad de huevos, se realizaron análisis de varianza (ANDEVA) factorial, para la primera y segunda generación por separado e integrado. Además para determinar diferencias estadísticas entre las dietas con los parámetros previamente mencionados, se realizó la prueba de Tukey. Para ajustar los datos de capacidad de oviposición y de longevidad de adultos a la distribución normal fueron previamente transformados mediante la ecuación cuadrática $(\sqrt{ } \mathrm{x}+0,5)$, para luego ser sometidos a estas pruebas. La prueba de $t \mathrm{de}$ Student se usó para determinar diferencias entre el ritmo de oviposición entre la primera y segunda generación de $C$. externa. Se empleó el paquete estadístico SPSS versión 14,0 .

\section{RESULTADOS}

Viabilidad de huevos. El porcentaje de viabilidad de huevos de $C$. externa provenientes de adultos a base de: la dieta estándar, $\mathrm{S}+\mathrm{K}$ y $\mathrm{M}+\mathrm{S}+\mathrm{K}$ de la segunda generación fue mayor en comparación al resto $(\mathrm{F}=38,9 ; \mathrm{p}=0,000)$ (Cuadro 4). La viabilidad de los huevos de $C$. externa de las dietas $\mathrm{L}, \mathrm{L}+\mathrm{K}$, y $\mathrm{S}+\mathrm{K}$ fueron mayores al resto $(\mathrm{F}=4,7 ; \mathrm{p}=0,002)$ (Cuadro 4$)$.

Capacidad de oviposición. Se determinó la cantidad total de huevos obtenidas de C. externa para cada dieta durante dos generaciones (Cuadro 5). El promedio de huevos en la dieta estándar de la primera generación, y $\mathrm{L}+\mathrm{M}, \mathrm{L}+\mathrm{K}, \mathrm{M}+\mathrm{K}$ de la segunda generación fueron mayores al resto de tratamientos $(\mathrm{F}=3,8 ; \mathrm{p}=0,000)$. Al evaluar la capacidad de oviposición integrada de $C$. externa, las dietas $\mathrm{L}, \mathrm{L}+\mathrm{M}$, $\mathrm{L}+\mathrm{K}$ y $\mathrm{M}+\mathrm{K}$ fueron mayores al resto de tratamientos $(\mathrm{F}=4,0 ; \mathrm{p}=0,000)$ (Cuadro 5).

Ritmo de oviposición. Se aprecia que para la primera generación, el ritmo de oviposición de las hembras alimentadas con las dietas: $\mathrm{L}+\mathrm{M} ; \mathrm{L}+\mathrm{S} ; \mathrm{L}+\mathrm{K} ; \mathrm{M}+\mathrm{K}$ y $\mathrm{S}+\mathrm{K}$ fue similar (Fig 1a-g), llegando a colocar la mayor cantidad de huevos a partir de la primera semana de su periodo de oviposición; para luego ir descendiendo paulatinamente hasta el fin de este periodo.

Para los tratamientos $\mathrm{M}+\mathrm{S}, \mathrm{M}+\mathrm{S}+\mathrm{K}$ y dieta estándar (Fig. 1e, 1h y 1a) la mayor cantidad de huevos se observaron a partir de la tercera y quinta semana respectivamente, para luego descender. Para la segunda generación, el ritmo de oviposición de las hembras alimentadas con las dietas: $\mathrm{L}+\mathrm{S} ; \mathrm{M}+\mathrm{S} ; \mathrm{M}+\mathrm{K} ; \mathrm{M}+\mathrm{S}+\mathrm{K}$; $\mathrm{S}+\mathrm{K}$ y dieta estándar (Fig. 1c, 1e, 1f, $1 \mathrm{~g}$ y 1h), es similar dándose entre la quinta y sexta semana los periodos de mayor cantidad de huevos. Para la dieta $\mathrm{L}+\mathrm{K}$ el periodo de mayor cantidad de huevos se dio a partir de la primera semana (Fig. 1d). 
Cuadro 4. Viabilidad de huevos de C. externa bajo ocho dietas artificiales.

\begin{tabular}{|c|c|c|c|c|c|c|}
\hline \multicolumn{3}{|c|}{ Primera generación } & \multicolumn{4}{|c|}{$1^{\text {era }}$ y $2^{\text {da }}$ generación integrada } \\
\hline Dieta & Prom & $\mathrm{DE}$ & Sig & Prom & $\mathrm{DE}$ & Sig \\
\hline $\mathrm{L}$ & 45 & 4,2 & cdef & 50,7 & 8,2 & $\mathrm{~b}$ \\
\hline $\mathrm{L}+\mathrm{M}$ & 37 & 1,4 & $\mathrm{a}$ & 43,3 & 7,2 & $\mathrm{ab}$ \\
\hline $\mathrm{L}+\mathrm{S}$ & 38,5 & 2,1 & $\mathrm{ab}$ & 40,5 & 2,6 & $\mathrm{a}$ \\
\hline $\mathrm{L}+\mathrm{K}$ & 52,5 & 0,7 & ghi & 50,7 & 2,1 & $\mathrm{~b}$ \\
\hline $\mathrm{M}+\mathrm{S}$ & 50 & 1,4 & fgh & 49,3 & 1,2 & $a b$ \\
\hline $\mathrm{M}+\mathrm{K}$ & 40 & 0 & $a b c$ & 46,3 & 7,2 & $a b$ \\
\hline $\mathrm{S}+\mathrm{K}$ & 47,5 & 0,7 & defg & 52 & 5,2 & $\mathrm{~b}$ \\
\hline $\mathrm{M}+\mathrm{S}+\mathrm{K}$ & 44 & 1,4 & bcde & 49,3 & 6,1 & $\mathrm{ab}$ \\
\hline \multicolumn{7}{|c|}{ Segunda generación } \\
\hline $\mathrm{L}$ & 58,5 & 0,7 & $\mathrm{j}$ & & & \\
\hline $\mathrm{L}+\mathrm{M}$ & 49,5 & 0,7 & efgh & & & \\
\hline $\mathrm{L}+\mathrm{S}$ & 42,5 & 0,7 & abcd & & & \\
\hline $\mathrm{L}+\mathrm{K}$ & 49 & 0 & efgh & & & \\
\hline $\mathrm{M}+\mathrm{S}$ & 48,5 & 0,7 & efg & & & \\
\hline $\mathrm{M}+\mathrm{K}$ & 52,5 & 0,7 & ghi & & & \\
\hline $\mathrm{S}+\mathrm{K}$ & 56,5 & 0,7 & $\mathrm{ij}$ & & & \\
\hline $\mathrm{M}+\mathrm{S}+\mathrm{K}$ & 54,5 & 0,7 & hij & & & \\
\hline
\end{tabular}

$\mathrm{L}=$ levadura de cerveza; $\mathrm{M}=$ maca; $\mathrm{S}=$ soya $\mathrm{K}=$ kiwicha . Prom = Promedio. $\mathrm{DE}=$ Desviación estándar. Sig $=$ Significancia. Primera generación $\left(T=24,2 \pm 3,2{ }^{\circ} \mathrm{C}\right)$. Segunda generación $(\mathrm{T}=20,6 \pm$ $\left.0,5^{\circ} \mathrm{C}\right)$. La primera y segunda generación han sido evaluadas en conjunto. Según Tukey $(\mathrm{p}=0,05)$ letras minúsculas iguales no difieren estadísticamente entre sí.

Comparando los ritmos de oviposición de las dos generaciones para cada dieta, se obtuvo una diferencia significativa para los días 8 y $43(\mathrm{t}=2,2 ; \mathrm{p}=0,04 \mathrm{yt}=5,4 ; \mathrm{p}$ $=0.000)$. Para la dieta $\mathrm{L}+\mathrm{M}$ (Fig. 1b) se obtuvieron diferencias en los días: $29(\mathrm{t}=$ $3,6 ; \mathrm{p}=0,03), 43(\mathrm{t}=3,8 ; \mathrm{p}=0,002), 50(\mathrm{t}=3,6 ; \mathrm{p}=0,02), 59(\mathrm{t}=4 ; \mathrm{p}=0,01), 66$ $(\mathrm{t}=4 ; \mathrm{p}=0,01), 73(\mathrm{t}=2,3 ; \mathrm{p}=0,03)$. En la dieta $\mathrm{M}+\mathrm{K}$ (Fig. 1f) se obtuvo diferencias en los días $1(\mathrm{t}=3,7 ; \mathrm{p}=0,003), 8(\mathrm{t}=3,9 ; \mathrm{p}=0,002), 29(\mathrm{t}=3,6 ; \mathrm{p}=$ $0,003), 36(\mathrm{t}=5,2 ; \mathrm{p}=0,000), 43(\mathrm{t}=4,2 ; \mathrm{p}=0,001) 50(\mathrm{t}=3,3 ; \mathrm{p}=0,005), 59(\mathrm{t}=$ $3,7 ; \mathrm{p}=0,002)$ y $66(\mathrm{t}=3,7 ; \mathrm{p}=0,003)$. Además para la dieta $\mathrm{S}+\mathrm{K}$ (Fig. 1g) se encontraron diferencias significativas en los días $12(\mathrm{t}=2,6 ; \mathrm{p}=0,01), 50(\mathrm{t}=2,6$; $\mathrm{p}=0,02), 59(\mathrm{t}=3,4 ; \mathrm{p}=0,004)$ y $66(\mathrm{t}=3,1 ; \mathrm{p}=0,008)$. Mientras que para el resto de dietas no se obtuvieron diferencias estadísticas significativas en diferentes fechas. 
Cuadro 5. Capacidad de oviposición de adultos de C. externa bajo ocho dietas artificiales.

\begin{tabular}{|c|c|c|c|c|c|c|}
\hline \multirow[b]{2}{*}{ Dieta } & \multicolumn{3}{|c|}{ Primera generación } & \multicolumn{3}{|c|}{$\begin{array}{c}1^{\text {era }} \text { y } 2^{\text {da }} \text { generación } \\
\text { integrada }\end{array}$} \\
\hline & Prom & $\mathrm{DE}$ & Sig & Prom & $\mathrm{DE}$ & Sig \\
\hline$\overline{\mathrm{L}}$ & 1061,1 & 391,4 & $\mathrm{~cd}$ & 794,1 & 499,8 & $\bar{b}$ \\
\hline $\mathrm{L}+\mathrm{M}$ & 676,8 & 373,9 & abcd & 814,7 & 387,1 & $\mathrm{~b}$ \\
\hline $\mathrm{L}+\mathrm{S}$ & 462,9 & 372,8 & $\mathrm{ab}$ & 436 & 264,7 & $\mathrm{a}$ \\
\hline $\mathrm{L}+\mathrm{K}$ & 835,6 & 267,3 & abcd & 888,9 & 221,5 & $\mathrm{~b}$ \\
\hline $\mathrm{M}+\mathrm{S}$ & 587,5 & 193,3 & abcd & 639,4 & 202,3 & $a b$ \\
\hline $\mathrm{M}+\mathrm{K}$ & 721,1 & 451,2 & abcd & 904,7 & 380,2 & $\mathrm{~b}$ \\
\hline $\mathrm{S}+\mathrm{K}$ & 547,9 & 241,1 & $a b c$ & 566 & 194,3 & $a b$ \\
\hline $\mathrm{M}+\mathrm{S}+\mathrm{K}$ & 638,0 & 260,5 & abcd & 683,8 & 283,8 & $\mathrm{ab}$ \\
\hline \multicolumn{7}{|c|}{ Segunda generación } \\
\hline $\mathrm{L}$ & 527,1 & 468,2 & $a b$ & & & \\
\hline $\mathrm{L}+\mathrm{M}$ & 952,8 & 371,2 & bcd & & & \\
\hline $\mathrm{L}+\mathrm{S}$ & 409,1 & 97,9 & $\mathrm{a}$ & & & \\
\hline $\mathrm{L}+\mathrm{K}$ & 942,3 & 165,1 & bcd & & & \\
\hline $\mathrm{M}+\mathrm{S}$ & 691,4 & 210,2 & abcd & & & \\
\hline $\mathrm{M}+\mathrm{K}$ & 1088,4 & 170,6 & $\mathrm{~b}$ & & & \\
\hline $\mathrm{S}+\mathrm{K}$ & 584,1 & 148,6 & abcd & & & \\
\hline $\mathrm{M}+\mathrm{S}+\mathrm{K}$ & 729,6 & 316,1 & abcd & & & \\
\hline
\end{tabular}

$\mathrm{L}=$ levadura de cerveza; $\mathrm{M}=$ maca; $\mathrm{S}=$ soya; $\mathrm{K}=$ kiwicha. Prom $=$ Promedio. $\mathrm{DE}=$ Desviación estándar. Sig $=$ Significancia. Primera generación $\left(T=24,2 \pm 3,2{ }^{\circ} \mathrm{C}\right)$. Segunda generación $(\mathrm{T}=20,6 \pm$ $\left.0,5^{\circ} \mathrm{C}\right)$. La primera y segunda generación han sido evaluadas en conjunto. Según Tukey $(\mathrm{p}=0,05)$ letras minúsculas iguales no difieren estadísticamente entre sí.

Periodo de pre-oviposición, oviposición y post-oviposición. El periodo de preoviposición para C. externa indicó diferencias significativas entre el tratamiento $\mathrm{L}+\mathrm{S}$ y $\mathrm{M}+\mathrm{K}+\mathrm{S}$ de la segunda generación con respecto a $\mathrm{L}$ y $\mathrm{M}+\mathrm{K}$ para la primera generación $(\mathrm{F}=3,1 ; \mathrm{p}=0,000)$ (Cuadro 6). El periodo de pre-oviposición para la primera y segunda generación integrada fue similar entre los ocho tratamientos $(\mathrm{F}=$ $2,4 ; p=0,027)$. El periodo de oviposición, en la primera generación fue similar entre los tratamientos, pero hay diferencias entre los tratamientos para la segunda generación, siendo mayor el periodo para las dietas $\mathrm{L}+\mathrm{M}, \mathrm{L}+\mathrm{K}, \mathrm{M}+\mathrm{S}, \mathrm{M}+\mathrm{K}$ y $\mathrm{M}+\mathrm{S}+\mathrm{K}$ con respecto al resto de tratamientos $(\mathrm{F}=5,2 ; \mathrm{p}=0,000)$ (Cuadro 6). El periodo de oviposición para la primera y segunda generación integrada fue similar entre los ocho tratamientos $(\mathrm{F}=2,7 ; \mathrm{p}=0,013)$. En el periodo de post-oviposición 
Cuadro 6. Periodos de pre-oviposición, oviposición y post-oviposición en días de adultos de C. externa bajo ocho dietas artificiales.

\begin{tabular}{|c|c|c|c|c|c|c|}
\hline \multirow[b]{2}{*}{ Dieta } & \multicolumn{6}{|c|}{ Días } \\
\hline & Pre I & Pre $^{1}$ & Ovi I & $\mathrm{Ovi}^{1}$ & Post I & Post $^{1}$ \\
\hline $\mathrm{L}$ & $9,3 \mathrm{a}$ & $11,6 a$ & $75,5 \mathrm{abc}$ & $59,1 \mathrm{a}$ & $5,4 a$ & $16,8 b$ \\
\hline $\mathrm{L}+\mathrm{M}$ & $10,4 a$ & $11,1 \mathrm{a}$ & $62,1 \mathrm{ab}$ & $85,1 \mathrm{a}$ & $2,6 a$ & $5,7 \mathrm{ab}$ \\
\hline $\mathrm{L}+\mathrm{S}$ & $12,8 \mathrm{abc}$ & $15,8 \mathrm{a}$ & $62,3 \mathrm{ab}$ & $72,8 \mathrm{a}$ & $8,1 \mathrm{ab}$ & $5,7 \mathrm{ab}$ \\
\hline $\mathrm{L}+\mathrm{K}$ & $11,8 \mathrm{abc}$ & $12,6 a$ & $79,6 \mathrm{abc}$ & $86,1 \mathrm{a}$ & $4,3 \mathrm{a}$ & $4,7 \mathrm{ab}$ \\
\hline $\mathrm{M}+\mathrm{S}$ & $11,1 \mathrm{ab}$ & $13,4 a$ & $81,5 \mathrm{abc}$ & $89,4 a$ & $5 a$ & $3,4 a b$ \\
\hline $\mathrm{M}+\mathrm{K}$ & $9,8 \mathrm{a}$ & $10,9 \mathrm{a}$ & $63,3 \mathrm{ab}$ & $80,4 a$ & $6,8 \mathrm{ab}$ & $4,4 a b$ \\
\hline $\mathrm{S}+\mathrm{K}$ & $11,3 \mathrm{ab}$ & $12,1 \mathrm{a}$ & $48,3 \mathrm{a}$ & $62,9 a$ & $1,6 \mathrm{a}$ & $2,1 \mathrm{a}$ \\
\hline $\mathrm{M}+\mathrm{S}+\mathrm{K}$ & $12,3 \mathrm{abc}$ & $15,1 \mathrm{a}$ & $66,6 \mathrm{abc}$ & $87,4 \mathrm{a}$ & $4,8 \mathrm{a}$ & $4,1 \mathrm{ab}$ \\
\hline Dieta & Pre II & & Ovi II & & Post II & \\
\hline $\mathrm{L}$ & $14,1 \mathrm{abc}$ & & $42,9 a$ & & $28,3 b$ & \\
\hline $\mathrm{L}+\mathrm{M}$ & $12 a b c$ & & $108,3 b$ & & $8,9 a b$ & \\
\hline $\mathrm{L}+\mathrm{S}$ & $19 b$ & & $83,4 a b c$ & & $3,3 \mathrm{a}$ & \\
\hline $\mathrm{L}+\mathrm{K}$ & $13,5 \mathrm{abc}$ & & $92,5 \mathrm{bc}$ & & $5,1 \mathrm{a}$ & \\
\hline $\mathrm{M}+\mathrm{S}$ & $15,6 \mathrm{abc}$ & & $97,4 \mathrm{bc}$ & & $1,9 a$ & \\
\hline $\mathrm{M}+\mathrm{K}$ & $12,1 \mathrm{abc}$ & & $97,5 \mathrm{bc}$ & & $2 a$ & \\
\hline $\mathrm{S}+\mathrm{K}$ & $12,9 \mathrm{abc}$ & & $77,6 \mathrm{abc}$ & & $2,5 \mathrm{a}$ & \\
\hline $\mathrm{M}+\mathrm{S}+\mathrm{K}$ & $18,1 \mathrm{bc}$ & & $108,1 b$ & & $3,4 \mathrm{a}$ & \\
\hline
\end{tabular}

$\mathrm{L}=$ levadura de cerveza; $\mathrm{M}=$ maca; $\mathrm{S}=$ soya; $\mathrm{K}=$ kiwicha. Primera generación $\left(\mathrm{T}=24,2 \pm 3,2{ }^{\circ} \mathrm{C}\right)$. Segunda generación $\left(\mathrm{T}=20,6 \pm 0,5{ }^{\circ} \mathrm{C}\right)$. Pre $=$ Pre-oviposición. Ovi $=$ Oviposición. Post $=$ Potoviposición. $1=1^{\text {era }}$ y $2^{\text {da }}$ generación integrada. Según Tukey $(\mathrm{p}=0,05)$ letras minúsculas iguales no difieren significativamente,

todos los tratamientos son similares entre sí, entre la primera y segunda generación. Solo la dieta $\mathrm{L}$ de la segunda generación fue diferente al resto de tratamientos $(\mathrm{F}=$ 2,$1 ; \mathrm{P}=0,013$ ) (Cuadro 6). El periodo de post-oviposición para la primera y segunda generación integrada fue similar entre los ocho tratamientos, siendo solo la dieta estándar mayor que el resto de tratamientos $(\mathrm{F}=2,1 ; \mathrm{p}=0,05)$.

Longevidad de hembra y macho. Las longevidades de hembras y machos de $C$. externa con las ocho dietas empleadas en la primera y segunda generación por separado difieren significativamente entre sí $(\mathrm{F}=3,7$ a 4,7; $\mathrm{p}=0,000)$ (Cuadro 7). Existieron diferencias en las longevidades para las hembras de la segunda generación en comparación con el resto de tratamientos, siendo las hembras de las dietas L+M 


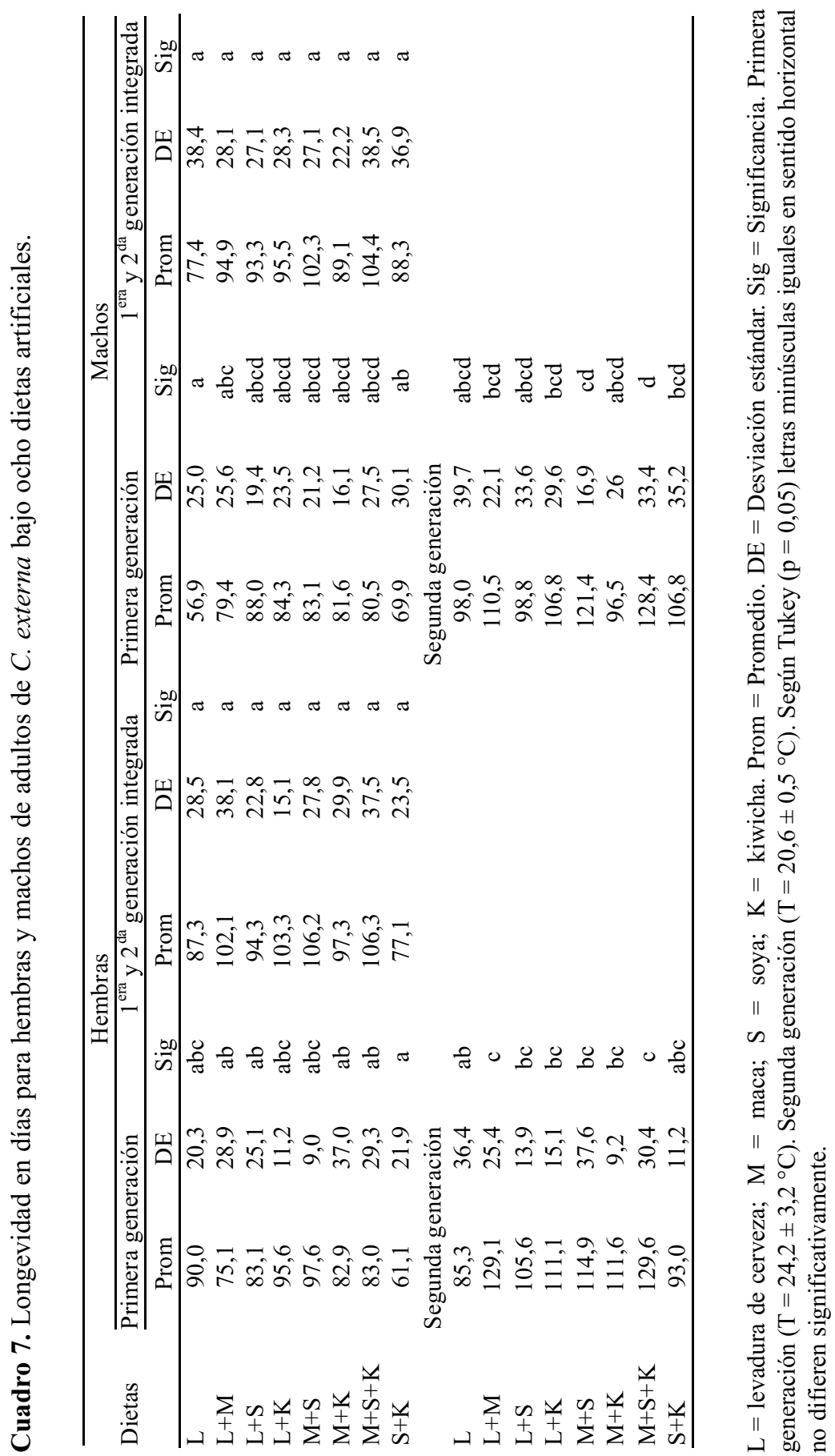


y $\mathrm{M}+\mathrm{S}+\mathrm{K}$ más longevas en comparación con las hembras de las otras catorce dietas $(\mathrm{F}=4,8 ; \mathrm{p}=0,000)$. No existieron diferencias significativas en la longevidad de las hembras bajo las ocho dietas artificiales $(\mathrm{F}=2,0 ; \mathrm{p}=0,06)$. La longevidad de los machos de las dietas $\mathrm{M}+\mathrm{K}$ y $\mathrm{M}+\mathrm{S}+\mathrm{K}$ de la segunda generación en relación al resto de dietas ensayadas fueron mayores $(\mathrm{F}=3,8 ; \mathrm{p}=0,000)$. No existieron diferencias significativas en la longevidad de los machos bajo las ocho dietas artificiales ( $\mathrm{F}=$ 1,$2 ; p=0,32$ ) (Cuadro 7). La longevidad en hembras y en machos se ve influenciada por la temperatura, siendo numéricamente mayor en la segunda generación $(24,2 \pm$ $\left.3,2{ }^{\circ} \mathrm{C}\right)$ en comparación con la primera $\left(20,6 \pm 0,5^{\circ} \mathrm{C}\right)$. Sin embargo, no existieron diferencias significativas en la temperatura promedio entre ambas generaciones $(\mathrm{t}=$ $2,2 ; \mathrm{p}=0,069)$. El mismo patrón se observó para la Humedad relativa entre ambas generaciones $(\mathrm{t}=0,8 ; \mathrm{p}=0,45)$ (Cuadro 1$)$.

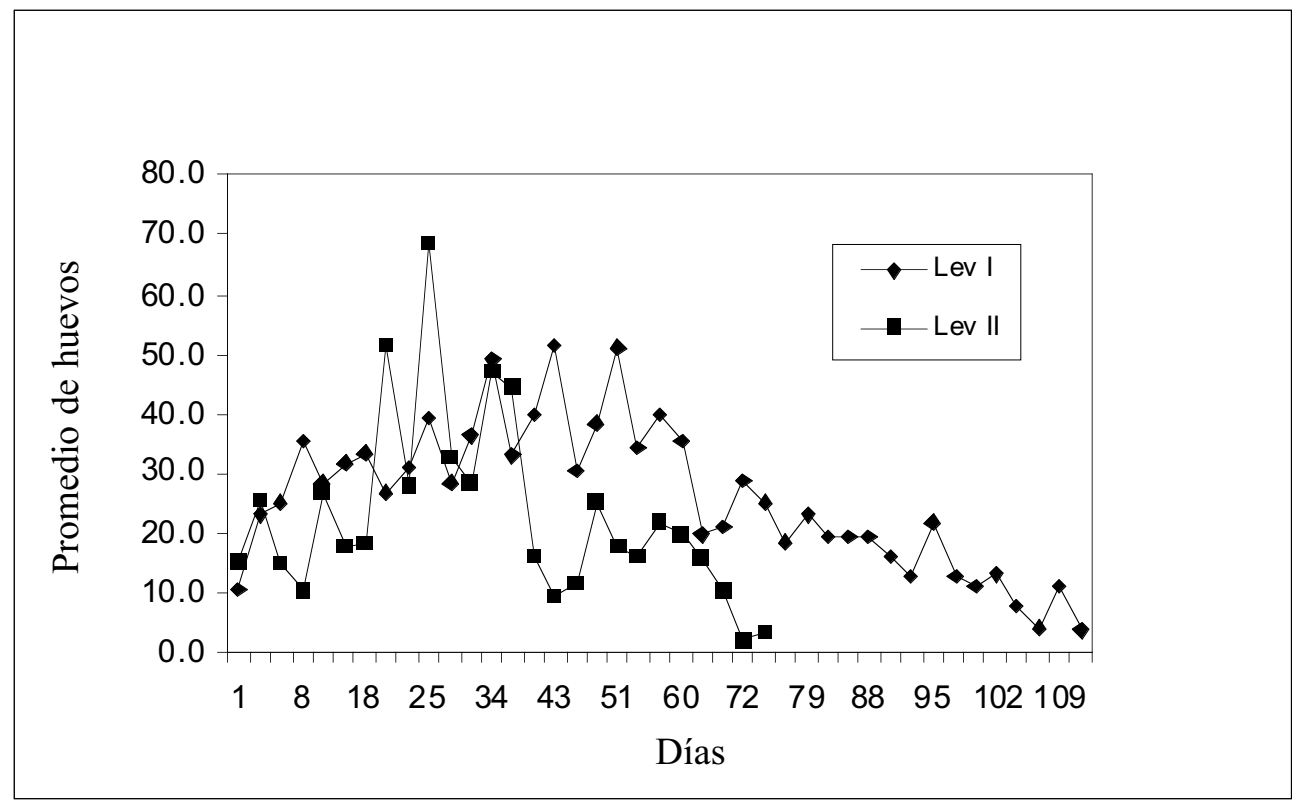

Figura 1a. Ritmo de oviposición de C. externa para las dos generaciones bajo dieta estándar. 


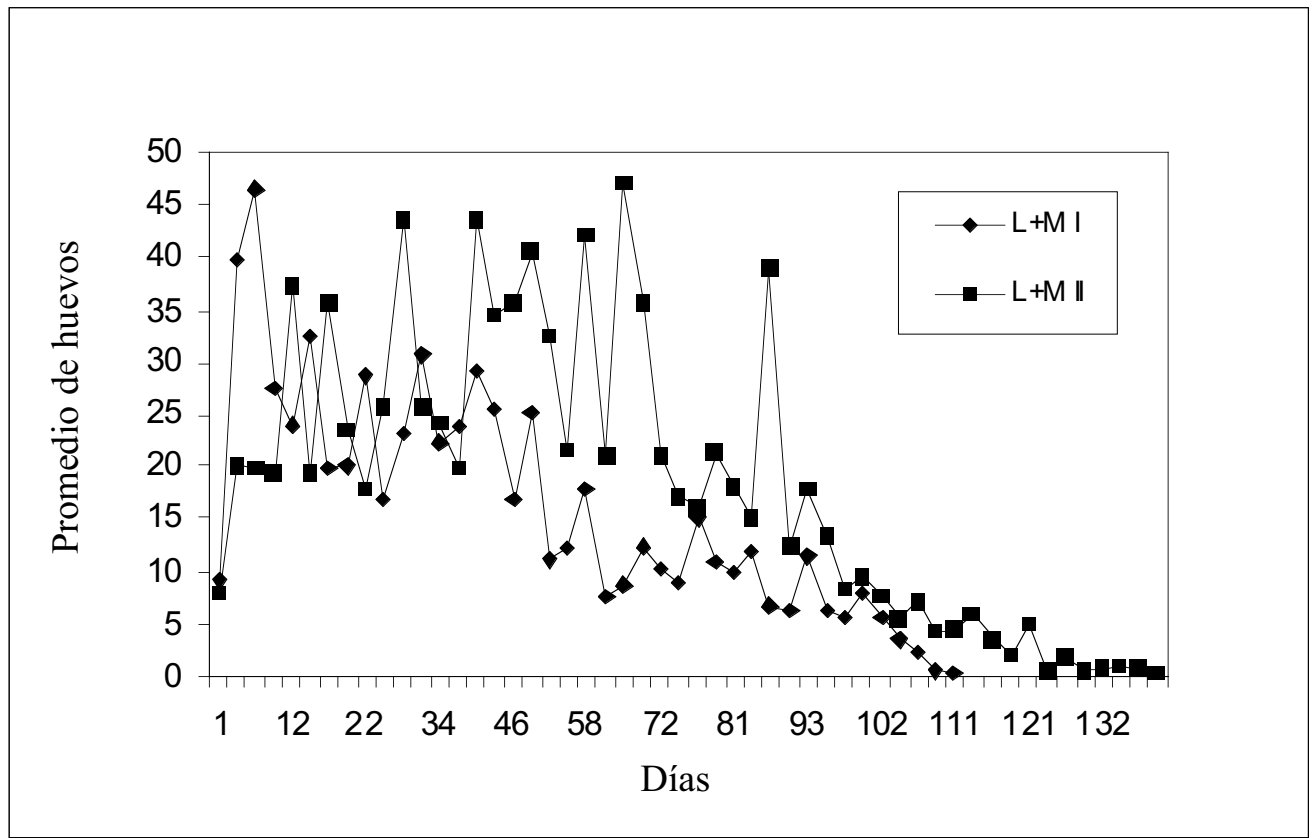

Figura 1b. Ritmo de oviposición de C. externa para las dos generaciones bajo: dieta L + M.

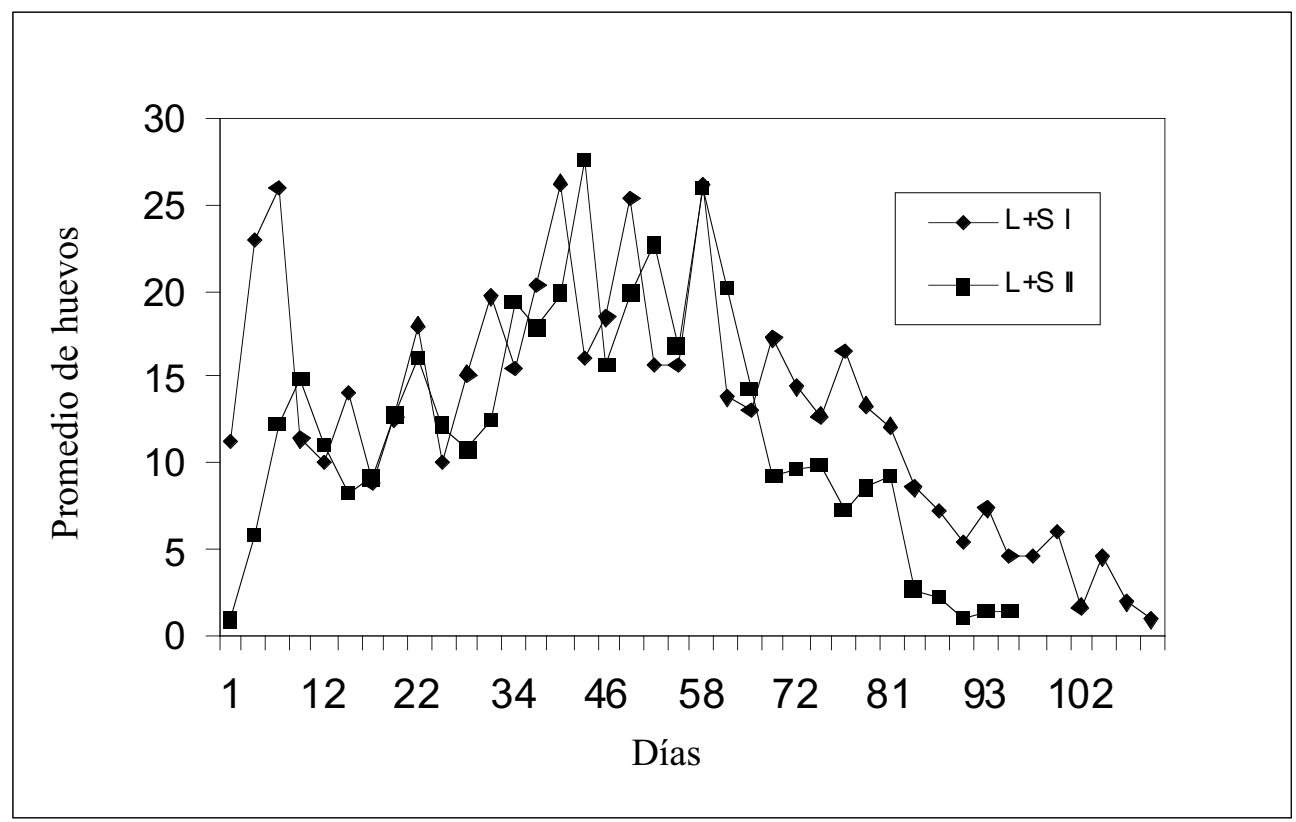

Figura 1c. Ritmo de oviposición de C. externa para las dos generaciones bajo: dieta $\mathrm{L}+\mathrm{S}$. 


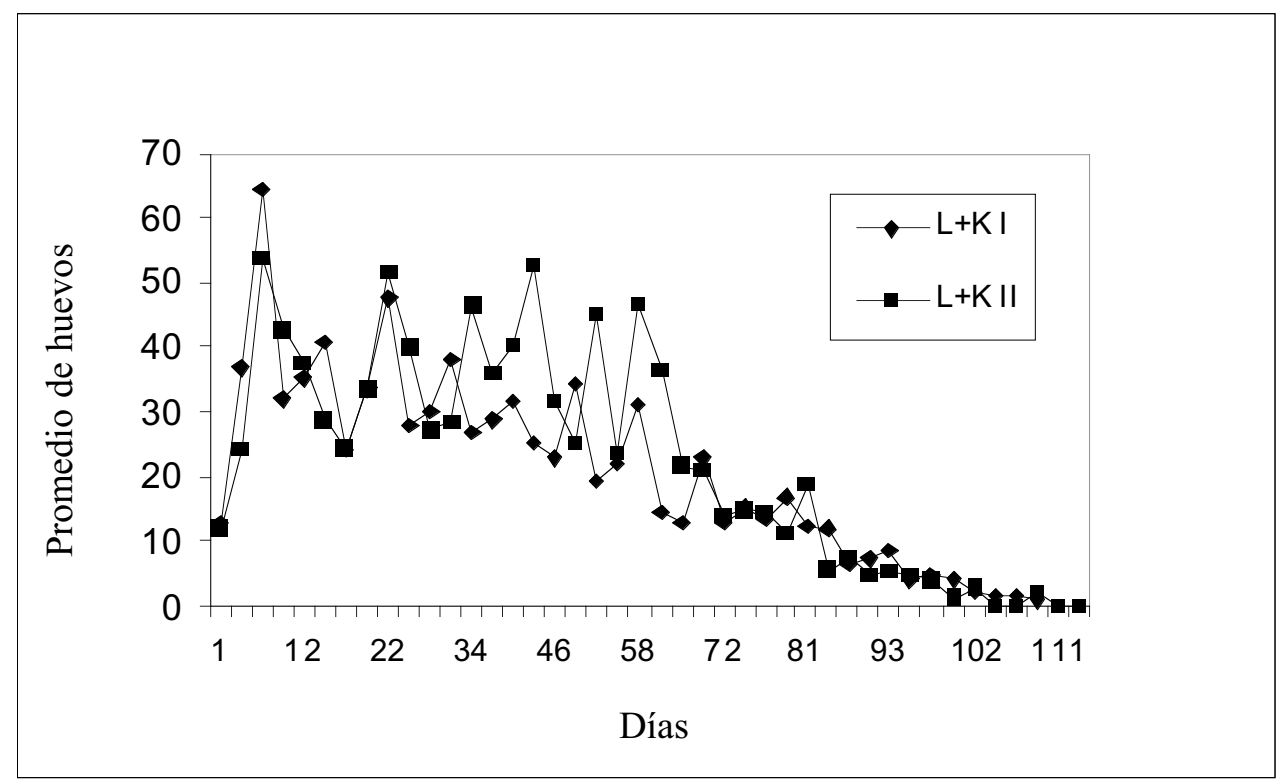

Figura 1d. Ritmo de oviposición de C. externa para las dos generaciones bajo: dieta L $+\mathrm{K}$.

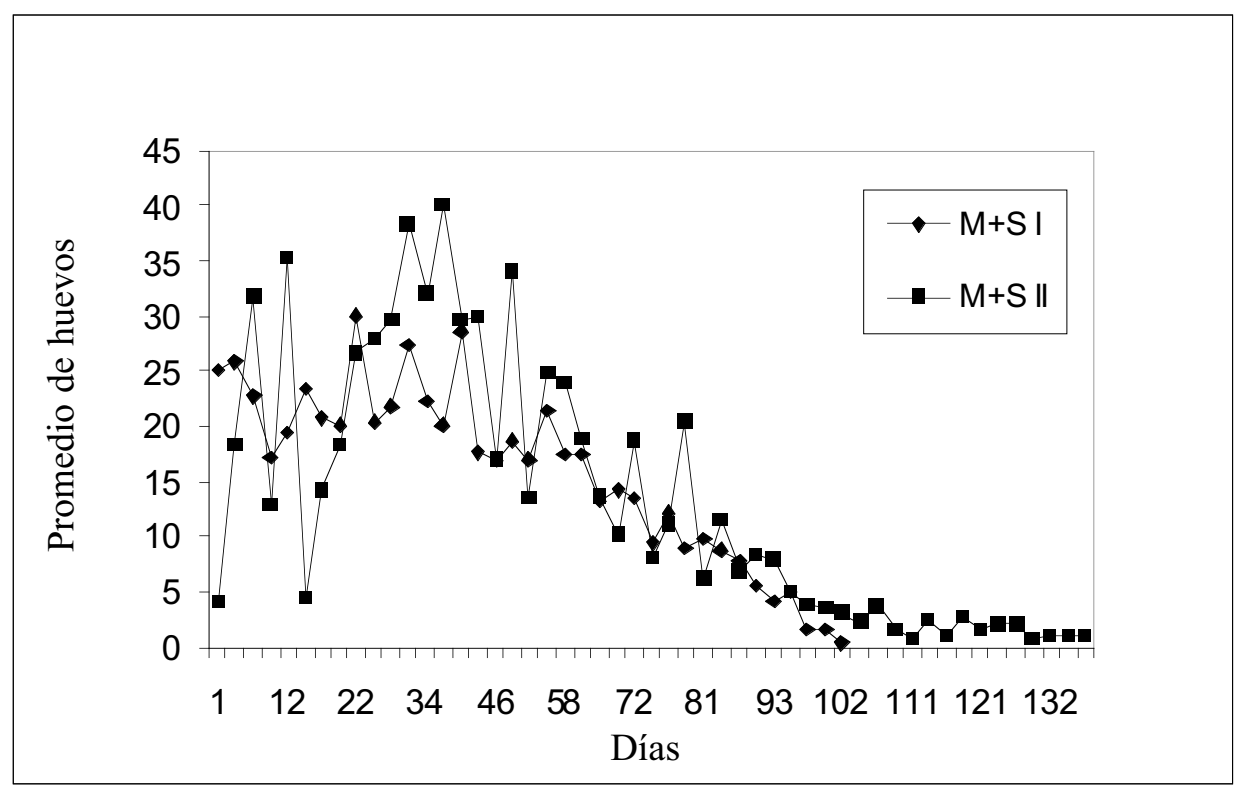

Figura 1e. Ritmo de oviposición de C. externa para las dos generaciones bajo: dieta $\mathrm{M}+\mathrm{S}$. 


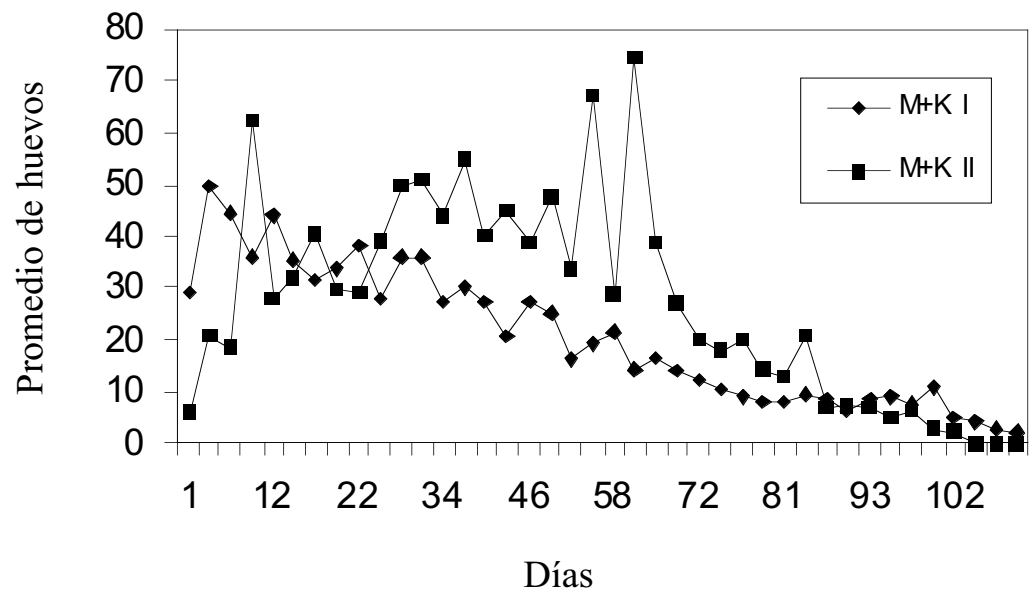

Figura 1f. Ritmo de oviposición de C. externa para las dos generaciones bajo: dieta $\mathrm{M}+\mathrm{K}$.

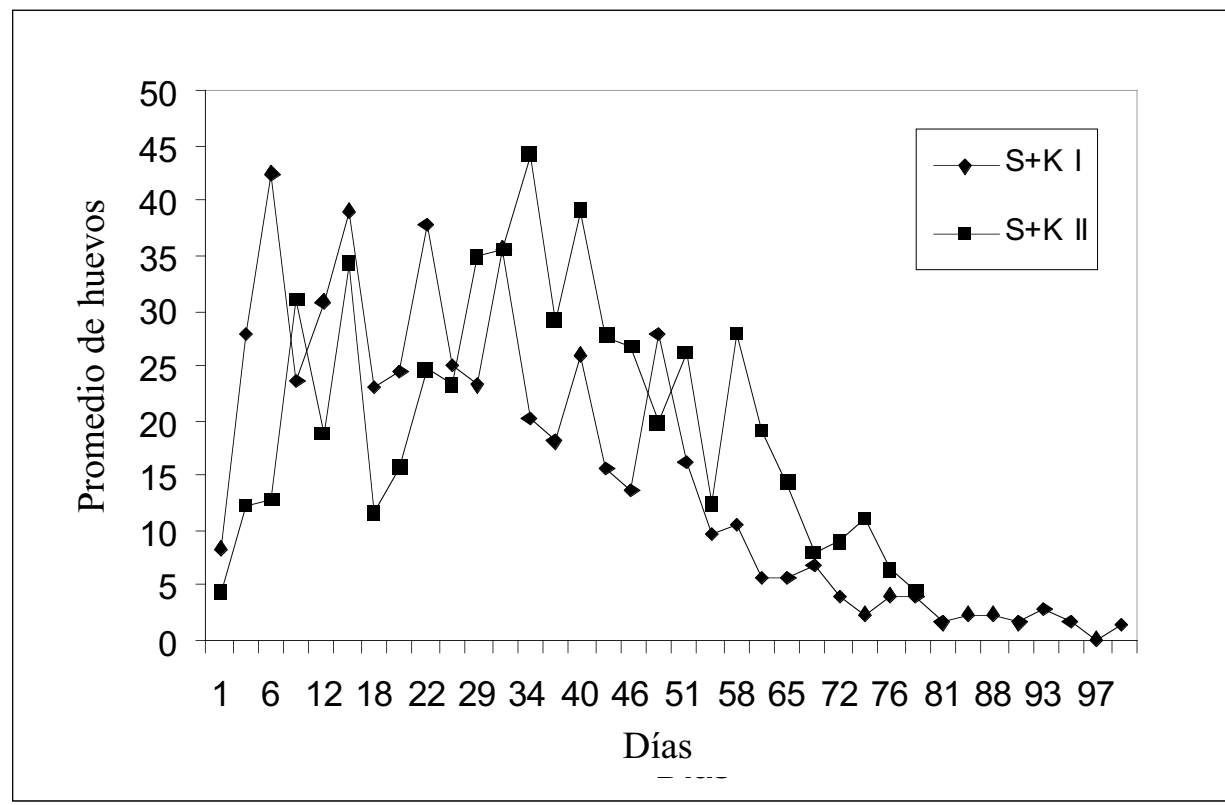

Figura 1g. Ritmo de oviposición de C. externa para las dos generaciones bajo: dieta $\mathrm{S}+\mathrm{K}$. 


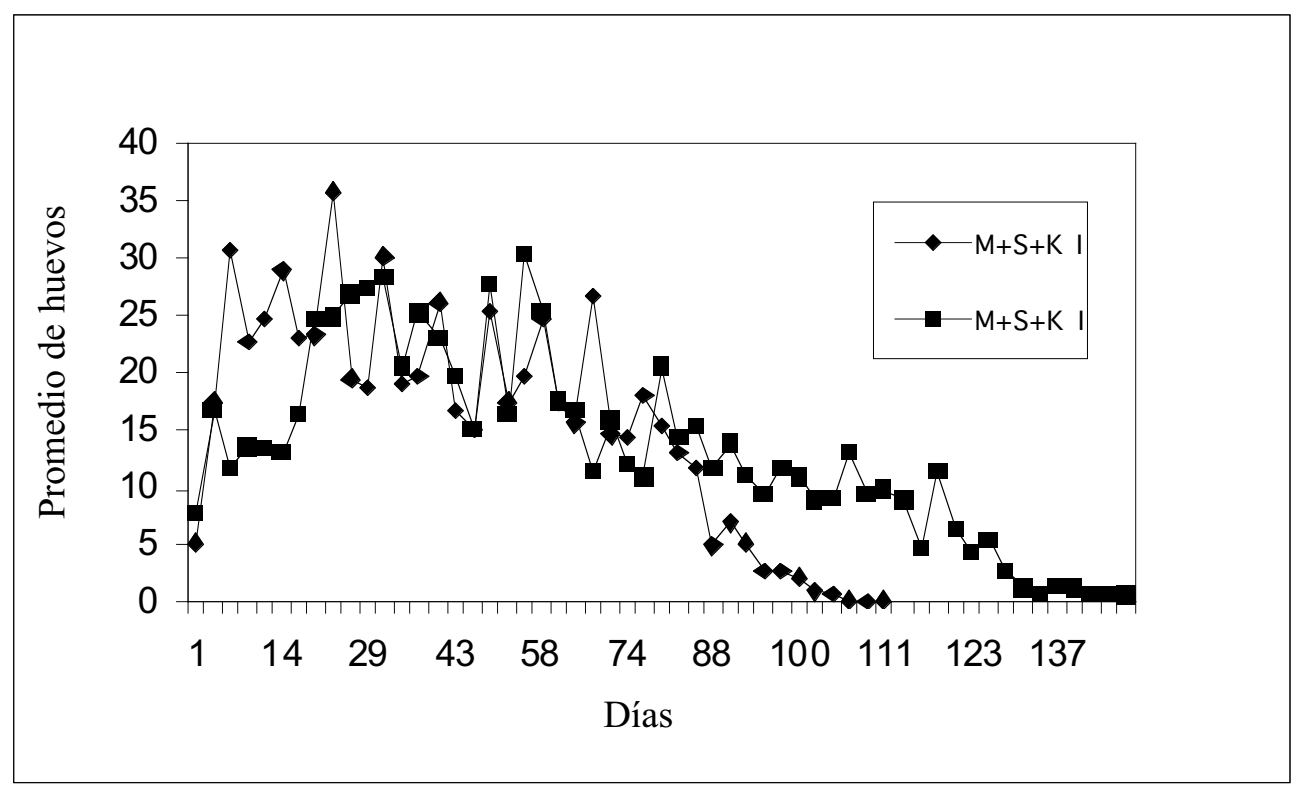

Figura 1h. Ritmo de oviposición de C. externa para las dos generaciones bajo: dieta $\mathrm{L}+\mathrm{M}+\mathrm{S}+\mathrm{K}$.

\section{DISCUSIÓN}

Viabilidad de huevos. En general, se observó una mayor viabilidad de huevos en la segunda generación de C. externa que en la primera generación (Cuadro 4). La viabilidad de los huevos de C. externa de las dietas con $\mathrm{L}, \mathrm{L}+\mathrm{K}$ y $\mathrm{S}+\mathrm{K}$ fue similar. Estos resultados muestran que la adición de soya, maca y kiwicha no favorecieron significativamente la viabilidad de los huevos en comparación con solo emplear levadura. Sin embargo, el menor costo de la harina de soya, maca y kiwicha y su disponibilidad en el mercado local en Perú son otras características que se debe tener en cuenta al seleccionar una adecuada dieta para la crianza masal de $C$. externa. Ulhaq et al. (2006) señalaron que la mezcla de levadura y miel es una dieta para adultos adecuada para la producción de huevos fértiles. Boregas et al. (2003) encontraron para $C$. externa una mayor viabilidad de huevos $(71 \%)$ procedentes de dietas artificiales. De igual manera, Barbosa et al. (2002) encontraron una mayor viabilidad de huevos para Ceraeochrysa everes (Bank, 1920) $(78,1 \%)$ al valor máximo encontrado en el presente estudio, al ser los adultos alimentados con levadura y miel (Cuadro 4). Ribeiro (1988) verificó una viabilidad media de 87,6 \% a $25{ }^{\circ} \mathrm{C}$ y Moraes (1989) encontró una viabilidad de 79\%. 
Capacidad de oviposición. Al comparar la fecundidad de los adultos de $C$. externa bajo las dietas $\mathrm{L}+\mathrm{M}, \mathrm{L}+\mathrm{K}$ y $\mathrm{M}+\mathrm{K}$ con la dieta estándar, indicó que con las tres dietas se obtuvieron cantidades estadísticamente similares de huevos totales (Cuadro 5). Por ende, la harina de maca y la harina de kiwicha serían un buen complemento nutricional de la levadura, por presentar un alto contenido de proteínas y de aminoácidos esenciales (Bressani et al. 1987, Dini et al. 1994, Escudero et al. 2004), obteniéndose así una adecuada dieta, la cual permite una mayor capacidad de oviposición (Lizárraga \& Cañedo 1988). Ulhaq et al. (2006) indican que el azúcar es un componente muy importante en la dieta de los adultos y que produce efectos pronunciados en la producción de huevos. En adición, Ulhaq et al. (2006) recomiendan levadura para una producción máxima de huevos. Boregas et al. (2003) encontraron en C. externa una fecundidad menor (387, 8 huevos/hembra) al solo emplear levadura de cerveza y miel. De igual forma, se ha encontrado en $C$. externa valores menores de fecundidad (350,4 huevos/hembra) al presente estudio con una dieta de levadura y miel (Barbosa et al. 2002). En Chrysoperla mediterranea (Hölzel, 1972) la fecundidad fue menor de 520,3 huevos/hembra (Carvalho et al. 2002). En C. carnea en una dieta que incluyó yema de huevo encontró una fecundidad menor de 168,3 huevos/hembra (Ulhaq et al. 2006). Vargas et al. (1988) al probar dietas artificiales sobre adultos de Ceraeochrysa cubana (Hagen, 1861), obtuvieron una menor fecundidad que el presente estudio. En oposición, en $C$. externa, una alta fecundidad se observó en la dieta a base de levadura de cerveza y a base de soya, en comparación a la de polen (Boregas et al. 2003). Macedo et al. (2003) para C. externa encontraron una alta fecundidad de 778,3 huevos/hembra con un fotoperíodo de $8 \mathrm{~h}$ de luz. Chang et al. (2000) observaron una alta capacidad de oviposición para C. carnea entre 629 y 870 huevos/hembra.

Ritmo de oviposición. Las hembras de C. externa no oviponen de forma constante durante su periodo de oviposición, su ritmo de oviposición es variable y está relacionado con la temperatura y la humedad relativa, como se puede ver en las Fig. 1a-h. En la primera generación los ritmos de oviposición se ven influenciados por las altas temperaturas de los meses de Marzo y Abril, pues en promedio los picos de máxima postura para la mayoría de los tratamientos se encuentran en la primeras tres semanas a diferencia de la dieta estándar (levadura de cerveza) que presenta su pico de máxima postura en la quinta semana, coincidiendo con los resultados obtenidos por Lizárraga \& Cañedo (1988) donde señalan que el pico máximo de postura de $C$. externa se encuentra entre la cuarta y quinta semana cuando es alimentada con levadura de cerveza. Barbosa et al. (2002) al alimentar a los adultos con levadura de cerveza y miel encontraron el pico máximo en la tercera semana. Lizarraga \& Cañedo (1988) y Boregas et al. (2003) indican que los ritmos de oviposición de C. externa son influenciados directamente por los diferentes tipos de dietas. 
Periodo de pre-oviposición, oviposición y post-oviposición. Los promedios de duración de los periodos de pre-oviposición, oviposición y post-oviposición para las dos generaciones de C. externa, se ven influenciados por la temperatura, alargándose a temperaturas bajas, lo que coincide con los resultados obtenidos por Núñez (1988b), quien registra periodos de pre-oviposición y oviposición menores en los meses de verano comparados con los de invierno, para dos especies de crisópidos, menciona periodos de $6 \pm 2,5$ días y $36 \pm 3,7$ días en verano, comparado con $10 \pm$ 1,9 días y $42 \pm 3,9$ días de invierno para C. externa; y periodos de $18 \pm 2,1$ días y 40 $\pm 4,6$ días en verano, comparado con $21 \pm 3,2$ y $47 \pm 5.2$ de invierno para Ceraeochrysa cincta (Schneider, 1851). En C. carnea, el periodo de pre-oviposición y de oviposición fue similar entre 3,3 a 13,9 y de 56,2 a 86,3 días (Chang et al. 2000). Carvalho et al. (2002) para C. mediterranea encontraron un menor periodo de preoviposición entre 5,8 y 8 días, y un periodo de oviposición similar a la dieta con L+ $\mathrm{M}, \mathrm{M}+\mathrm{K}$ y $\mathrm{M}+\mathrm{S}+\mathrm{K}$ de 100 días.

Longevidad de adultos. La longevidad tanto en hembras como en machos se ve influenciada por la temperatura, siendo mayor en la segunda generación desarrollada con una temperatura promedio de $20,6^{\circ} \mathrm{C}$ en comparación con la primera generación con temperatura de $24,2{ }^{\circ} \mathrm{C}$ (Cuadro 7). Resultados similares obtuvo Núñez (1988b) que registra una mayor longevidad de hembras y machos de C. externa en los meses de invierno en comparación con lo meses de verano ( $49 \pm 3,8$ y $31 \pm 4,2$ días en verano, en comparación con $56 \pm 4,1$ y $33 \pm 2,9$ días en invierno). Lira \& Batista (2006) para C. externa alimentadas con levadura de cerveza y miel, han encontrado que la longevidad de los machos fue de 66,38 días y de las hembras fue de 82,38. Murata (1996) obtuvo que las hembras de C. externa viven más que los machos. Otros autores han registrado una mayor longevidad para las hembras alimentadas con levadura de cerveza que para machos (Boregas et al. 2003). Nuestros resultados coinciden con los resultados obtenidos por Núñez (1988b) que registra mayor longevidad en hembras que en machos. Opuestamente, Carvalho et al. (2002) para C. mediterranea encontró un mayor longevidad para machos que para hembras, de 138,3 y 117,8 días, respectivamente. Ulhaq et al. (2006) encontraron que la longevidad de los machos y hembras de C. carnea fue similar, 27,7 y 26,9 días, respectivamente. La longevidad está en función de la especie y de las condiciones bióticas y abióticas a las cuales está sometido el insecto (Lira \& Batista 2006). La nutrición del adulto es un factor muy importante que influye en la longevidad de los insectos (Ulhaq et al. 2006).

Las ocho dietas evaluadas obtuvieron una elevada viabilidad de huevos en condiciones de laboratorio. Sin embargo, las dietas estandarizada a base de levadura, levadura + kiwicha, y soya + kiwicha obtuvieron una alta viabilidad de huevos. Las dietas a base de levadura, levadura + maca, levadura + kiwicha, y a base de maca y kiwicha fueron con las que se obtuvieron la mayor capacidad de oviposición. En 
general, no existieron diferencias significativas entre el periodo de pre-oviposición, oviposición y post-oviposición bajo las ocho dietas artificiales para C. externa, pero con tendencias a ser más altos en la segunda generación. Las dietas de levadura con maca, levadura, maca, soya y kiwicha permitieron un aumento en la longevidad de las hembras y machos para la segunda generación.

\section{LITERATURA CITADA}

Barbosa, L.R., S. de Freitas \& A.M. Auad. 2002. Capacidade reproductive e viabilidade de ovos de Ceraeochrysa everes (Banks, 1920) (Neuroptera: Chrysopidae) em diferentes condições de acasalamento. Ciênc. Agrotec. 26: 466-471.

Boregas, K.G.B., C.F. Carvalho \& B. Souza. 2003. Aspectos biológicos de Chrysoperla externa (Hagen, 1861) (Neuroptera; Chrysopidae) em casa-de-vegetacao. Ciênc. Agrotec. 27: 7-16.

Brack, E. A. 2003. Perú: Diez mil años de domesticación. Ed. Bruño. Lima. 160 pp.

Bressani, R., J.M. Gonzáles, J. Zuñiga, M. Breuner \& L.G. Elias. 1987. Yield, selected chemical composition and nutritive value of 14 selections of Amaranth grain representing four species. J. Sci. Food Agric. 38: 347-356.

Brodbeck, B., P. Andersen, R. Mizell \& S. Oden. 2004. Comparative nutrition and developmental biology of xylem-feeding leafhopper reared on four genotypes of Glycine max. Environ. Entomol. 33: 165-173.

Bruni, R., A. Medici, A. Guerrini, S. Scalia, F. Poli, M. Muzzoli \& G. Sacchetti. 2001. Wild Amaranthus caudatus seed oil, a nutriceutical resource from Ecuadorian flora. $J$. Agric. Food Chem. 49: 5455-5460.

Campoverde, E., M. Marquez \& J. Castro. 2002. Acción de la Maca Lepidium peruvianum en el ciclo evolutivo de Chrysoperla externa (Neuroptera: Chrysopidae) en condiciones de laboratorio. Pp. 55. In: XLIV Convención Nacional de Entomología. Resúmenes. Sociedad Peruana de Entomología. Lima, Perú.

Canales, M., J. Aguilar, A. Prada, A. Marcelo, C. Huaman \& L. Carvajal. 2000. Nutricional evaluation of Lepidium meyenii (Maca) in albino mice and their descendants. Arch. Latinoam. Nutr. 50:126-133.

Cardoso, J. T. \& S.M.N. Lazzari. 2003. Development and consumption capacity of Chrysoperla externa (Hagen) (Neuroptera, Chrysopidae) fed with Cinara spp. (Hemiptera: Aphididae) under three temperatures. Rev. Bras. Zool. 20: 573-576.

Carvalho, C.F., M. Canard \& C. Alauzet. 2002. Influence of the density of Chrysoperla mediterranea (Hölzel, 1972) (Neuroptera: Chrysopidae) adults on its laboratory reproduction potential. Acta zool. Hung. 48: 61-65.

Chang, Y.F., M.J. Tauber, C. A. Tauber \& J.P. Nyrop. 2000. Interpopulation variation in Chrysoperla carnea reproduction: implications for mass-rearing and storage. Entomol. Exp. Appl. 95: 293-302.

Chávez-Jáuregui, R.N., M.E.M.P. Silva \& J.A.G. Áreas. 2000. Extrusion cooking process for Amaranth (Amaranthus caudatus L.). J. Food Science 65: 1009-1015. 
Dini, A., G. Migliuolo, L. Rastrelli, P. Saturnino \& D. Schettino. 1994. Chemical composition of Lepidium meyenii. Food Chem. 49: 347-349.

Escudero, N.L., M.L. Arellano, J.M. Luco, M.S. Gimenez \& S.I. Mucciarelli. 2004. Comparison of the chemical composition and nutritional value of Amaranthus cruentus flour and its protein concentrate. Plants Food Human Nutr. 59: 15-21.

Gonzáles, G.F. \& L.G. Jr. Valerio. 2006. Medicinal plants from Peru: a review of plants as potencial agents against cancer. Anticancer Agents Med. Chem. 6: 429-444.

Iannacone, J., L. Alvariño, J.C. Soto \& C. Salcedo. 2007. Efecto toxicológico del "Sachayoco" Paullinia clavigera (Sapindaceae) sobre Daphnia magna, y sobre dos controladores biológicos de plagas agrícolas. J. Braz. Soc. Ecotoxicol. 2:15-25.

Iannacone, J. \& G. Lamas. 2002. Efecto de dos extractos botánicos y un insecticida convencional sobre el depredador Chrysoperla externa. Manejo Integrado de Plagas y Agroecología (Costa Rica), 65: 92-101

- 2003. Efectos toxicológicos de Molle (Schinus molle) y Lantana (Lantana camara) sobre Chrysoperla externa (Neuroptera: Chrysopidae), Trichogramma pintoi (Hymenoptera: Trichogrammatidae) y Copidosoma koehleri (Hymenoptera: Encyrtidae) en el Perú. Agric. Téc. (Chile) 63: 347-360.

Iannacone, J. \& Y. Murrugarra. 2000. Fluctuación poblacional del predador Metacanthus tenellus Stal (Heteroptera: Berytidae) por los insecticidas botánicos rotenona y neem en el cultivo de tomate en el Perú. Rev. Colomb. Entomol. 26: 89-97.

Karr-Lilienthal, L.K., L.L. Bauer, P.L. Utterback, K.E. Zinn, R.L. Frazier, C.M. Parson \& GT.C. Jr. Fahey. 2006. Chemical composition and nutricional quality of soybean meals prepared by extruder/expeller processing for use in poultry diets. J. Agric. Food Chem. 54: 8108-8014.

Lira, R.S. \& J.L. Batista. 2006. Aspectos biológicos de Chrysoperla externa alimentados com pulgões da erva-doce. Bio. Terra 6: 20-35.

Lizárraga, A. \& D. Cañedo. 1988. Dietas artificiales para la crianza en laboratorio de Chrysoperla externa (Hagen) (Neuroptera: Chrysopidae). Rev. per. Ent. 31: 83-85.

López-Fando, A., M.P. Gómez-Serranillos, I. Iglesias, O. Lock, U.P. Upamayta \& M.E. Carretero. 2004. Lepidium peruvianum Chacon restores homeostasis impaired by restraint stress. Phytother. Res. 18: 471-474.

Macedo, L.P.M., B. Souza, C.F. Carvalho \& C. C. Ecole. 2003. Influencia do fotoperíodo no desenvolvimento e na reprodução de Chrysoperla externa (Hagen) (Neuroptera: Chrysopidae). Neotropical Entomol. 32: 91-96.

Mahmoud, A.A., S.S. Natarajan, J.O. Bennett, T.P. Mawhinney, W.J. Wiebold \& H.B. Krishnan. 2006. Effect of six decades of selective breeding on soybean protein composition and quality: a biochemical and molecular analysis. J. Agric. Food Chem. 54: 3916-3922.

Martin, P., R. Ridway \& C. Schuetzer. 1978. Physical and biological evaluations of an encapsulated diet for rearing Chrysopa carnea. Florida Entomol. 61: 144-152

Medina P., F. Budia, P. Del Estal \& E. Viñuela. 2003. Effects of three modern insecticides, pyriproxifen, spinosad and tebufenozide, on survival and reproduction of Chrysoperla carnea adults. Ann. Appl. Biol. 142: 55-61. 
Miller, G.L., J.D. Oswald \& D.R. Miller. 2004. Lacewings and scale insects: a review of predator/prey associations between the Neuropterida and Coccoidea (Insecta: Neuroptera, Raphidioptera, Hemiptera). Ann. Entomol. Soc. Am. 97: 1103-1125.

Moraes, J.C. 1989. Aspectos biológicos e selectividade de algunas acaricidas a Ceraeochrysa cubana (Hagen, 1861) (Neuroptera: Chrysopidae) em laboratório. Dissertação (mestrado em Fitossanidade). Escola Superior de Agricultura de Lavras, Lavras, MG. 86 pp.

Murata, A.T. 1996. Utilization of Sitotroga cerealella adults (Lepidoptera: Gelechiidae) for chrysopid larvae rearing. Pp. 42. In: Simposio de Controle biológico. Foz do Iguaçu. Resumos. Foz do Iguaçu.

Nuñez, E. 1985. Primer registro y utilización en el Perú de Chrysoperla externa (Hagen) y Cereaochrysa cincta (Schneider). Informativo del área andina 4(1). IICA. 19 pp.

1988a. Chrysopidae (Neuroptera) del Perú y sus especies más comunes. Rev. per. Ent. 31: 69-75.

. 1988b. Ciclo biológico y crianza de Chrysoperla externa y Ceraeochrysa cincta (Neuroptera, Chrysopidae). Rev. per. Ent. 31: 76-82.

Nuñez, E. \& J. Pardo. 2002. Contribución al conocimiento de los Chrysopidae: taxonomía, biología, ecología y manejo. Pp. 25-40. In: Memorias Sociedad Colombiana de Entomología (SOCOLEN) XXIX Congreso, SOCOLEN. Montería, Colombia.

Ribeiro, M.J. 1988. Biologia de Chrysoperla externa (Haguen, 1861) (Neuroptera: Chrysopidae) alimentada com diferentes dietas. Dissertação (mestrado em Fitossanidade). Escola Superior de Agricultura de Lavras, Lavras-MG. 131 pp.

Ridway, R., R. Morrison \& M. Badgley. 1970. Mass rearing a green lacewing. J. Econ. Entomol. 63: 834-836.

Tassan, R., K. Hagen \& F. Sawall. 1979. The influence of field food sprays on the egg production rate of Chrysopa carnea. Environ. Entomol. 8: 81-85.

Ulhaq, M.M., A. Sattar, Z. Salihah, A. Farid, A. Usman \& S.U.K. Khattak. 2006. Effect of different artificial diets on the biology of adult green lacewing (Chrysoperla carnea Stephens.). Songklanakarin J. Sci. Technol. 28: 1-8.

Valerio, L.G. Jr. \& G.F. Gonzáles. 2005. Toxicological aspects of the South American herbs cat's claw (Uncaria tomentosa) and Maca (Lepidium meyenii): a critical synopsis. Toxicol. Rev. 24: 11-35.

Vanderzant, E. 1969. An artificial diet for larvae and adults of Chrysopa carnea an insect predator of crop pest. J. Econ. Entomol. 62: 256-257.

Vanderzant, E. 1973. Improvements in the rearing diet for Chrysopa carnea and the amino acid requeriments for growth. J. Econ. Entomol. 66: 336-338.

Vargas, C., E. Luque \& A. Villanueva. 1988. Uso de dietas artificiales para la cría de larvas y adultos de Ceraeochrysa cubana (Hagen) (Neuroptera: Chrysopidae). Agronomía Colomb. 5: 60-68. 